\title{
(Des)vinculações de Planos Municipais de Educação metropolitanos com outros instrumentos de gestão local da educação
}

Donaldo Bello de Souza'

Alzira Batalha Alcântara"l

I- Universidade do Estado do Rio de Janeiro, Rio de Janeiro, RJ, Brasil. Contato: donaldobello@gmail.com II- Universidade do Estado do Rio de Janeiro / Universidade Estácio de Sá, Rio de Janeiro, RJ, Brasil.

Contato: alzirabatalha@hotmail.com

\section{Resumo}

É possível afirmar que são poucos os estudos sobre os Planos Municipais de Educação (PMEs) aprovados no Brasil ao longo do período de vigência do PNE 2001-2010, especialmente os relativos às Regiões Metropolitanas (RMs), cuja necessidade de conhecimento se torna mais evidente em face dos desafios postos pelo PNE 20142024 à reformulação desses planos locais. Assim, o presente artigo visa à análise das vinculações previstas em PMEs em relação a outros instrumentos de gestão local da educação, tomando por base empírica os planos pertencentes a dez municípios da RM do estado do Rio de Janeiro, aprovados no período 2001-2012, com vistas ao delineamento de eventuais problemas internos, também relacionados ao planejamento em escala metropolitana. Trata-se de um estudo de caráter exploratório, metodologicamente ancorado na análise de conteúdo de documentos legislativos, cujas conclusões mais gerais apontam, de um lado, nítidas desvinculações em relação ao conjunto de instrumentos de gestão considerados nas análises, e, de outro, ausência de um enfoque regional-metropolitano nesses mesmos planos. Evidencia, ainda, que essas desarticulações locais e regionais constituem importantes reptos a serem superados com vistas à adequação desses planos ao novo PNE, postulando que tais enlaces são passíveis de previsão a partir da compreensão de que um plano de educação não constitui um instrumento independente e sufıciente de gestão e, embora se afıgure numa espécie de registro de coordenação e sistematização das decisões previstas para a condução das políticas educacionais no município, é parte integrante dessas mesmas políticas e não estranho a elas.

\section{Palavras-chave}

Plano Municipal de Educação (PME) - Plano Nacional de Educação (PNE) - Planejamento educacional - Planejamento metropolitano Rio de Janeiro. 


\title{
(Dis)association between metropolitan Municipal Education Plans and other tools of local educational management
}

Donaldo Bello de Souza'

Alzira Batalha Alcântara"

\begin{abstract}
It is possible to affirm that there are few studies on the Municipal Education Plans approved in Brazil over the period the National Education Plan 2001-2010 was in force, particularly those for the Metropolitan Regions, about which the need for knowledge becomes more evident in the face of the challenges proposed by the National Education Plan 2014-2024 to reformulate these local plans. Thus, this article intends to analyze the links provided by Municipal Education Plans in relation to other tools of local educational management taking as empirical basis the plans of ten municipalities in the metropolitan area of Rio de Janeiro state approved in 20012012, aiming to outline possible internal problems, also related to planning on a metropolitan scale. It is a study with exploratory character, methodologically based on the analysis of the content of legal documents. Its general conclusions indicate, on the one hand, clear disassociations from the management tools considered in the analysis and, on the other hand, the absence a regional-metropolitan focus in those plans. It also evidences that these local and regional disassociations are major challenges to the adjustment of these plans to the new National Education Plan, postulating that such links can be provided from the understanding that an education plan is not an independent and sufficient management tool and that, although it appears to be a type of record of coordination and systematization of decisions provided to conduct the educational policies in the municipality, it is an integral part of these policies and it is not stranger to them.
\end{abstract}

\section{Keywords}

Municipal Education Plan (PME) - National Education Plan (PNE)

- Educational planning - Metropolitan planning - Rio de Janeiro.

I- Universidade do Estado do Rio de Janeiro, Rio de Janeiro, RJ, Brasil. Contact: donaldobello@gmail.com II- Universidade do Estado do Rio de Janeiro / Universidade Estácio de Sá, Rio de Janeiro, RJ, Brasil.

Contact: alzirabatalha@hotmail.com 


\section{Introdução}

Dentre o conjunto de desafios que o novo Plano Nacional de Educação (PNE) suscita ao planejamento educacional do Brasil, para o período 2014-2024 - Lei no 13.005, de 25 de junho de 2014 (BRASIL, 2014) -, destaca-se a determinação de que:

A União, os Estados, o Distrito Federal e os Municípios atuarão em regime de colaboração, visando ao alcance das metas e à implementação das estratégias objeto deste Plano. (BRASIL, 2014, art. 7º).

Além disso, culmina na indicação de que :

Os Estados, o Distrito Federal e os Municípios deverão elaborar seus correspondentes planos de educação, ou adequar os planos já aprovados em lei, em consonância com as diretrizes, metas e estratégias previstas neste PNE, no prazo de 1 (um) ano contado da publicação desta Lei. (BRASIL, 2014, art. 8).

Sobre os planos municipais de educação (PMEs) aprovados no país, resultantes dos desdobramentos dos PNE 2001-2010 que, em tese, deveriam apresentar articulações com as especificidades do planejamento local da educação, é possível afirmar, conforme identificado em levantamento exaustivo realizado por Souza e Sousa (2012), que pouco se sabe a seu respeito, isto em função da escassez e características dos estudos que os tomam por alvo. Segundo Souza e Duarte (2014), até o último ano de vigência do PNE 2001-2010, apenas seis (22,2\%) das 27 unidades federativas expunham exame científico de pelo menos um dos seus PMEs, a saber: Rio Grande do Sul (DRABACH; MIRANDA, 2005; ASSUMPÇÃO, 2006; GHENO, 2008; WERLE; BARCELLOS, 2008), Paraná (SANTOS, 2004), Rio de Janeiro (VILLELA, 2008), Mato Grosso do Sul (BARBOZA, 2008), Alagoas (OLIVEIRA;
ARAGÃO, 2010) e Rio Grande do Norte (SOUZA, 2006). Caracteristicamente, essas pesquisas ocupam-se do exame do caráter mais ou menos democrático relativo ao processo de construção do plano, visando à análise do nível e grau da participação sociopolítica local, dedicando pouca ou nenhuma atenção ao conteúdo desse instrumento, tampouco à sua avaliação (SOUZA; DUARTE, 2014).

No que tange à realidade dos PMEs em Regiões Metropolitanas (RMs) do Brasil, a disponibilização de estudos se mostra ainda mais precária, embora pesquisas como as de Martins, Pimenta e Novaes (2014), que enfocam os princípios e as diretrizes políticas dos PMEs de municípios pertencentes à RM paulista, estejam sinalizando importantes tendências investigativas do campo. Decerto, tal insuficiência reflete entraves de um contexto mais amplo, relativo à ausência de uma tradição de planejamento educacional intermunicipal no Brasil, mesmo em face de um contexto de certa descentralização da gestão dos serviços públicos que, pelo menos de forma potencial, haveria de resultar numa maior colaboração no interior dessas regiões, em paralelo à diminuição dos processos de regulação centralizados pelos estados ou pela União (LACERDA, 2011), já que se trata de cidades ditas intermunicipais, que enfrentam problemas urbanos complexos e, a um só tempo, desafios de gestão conjunta nas mais variadas áreas dos serviços públicos (CARVALHO; PASTERNAK; BOGUS, 2010; MARICATO, 2000, 2011).

Considerando o quadro acima traçado, o presente artigo visa à análise das vinculações previstas nos PMEs em relação a outros instrumentos de gestão local da educação, tomando por base empírica os planos pertencentes a dez municípios da RM do estado do Rio de Janeiro, aprovados pelas Câmaras Municipais correspondentes no período 2001-2012, com vistas ao delineamento dos problemas internos que apresentam, também para o planejamento em escala metropolitana. Na atualidade, esta RM é composta por 19 municípios (RIO DE JANEIRO, 
2010) - 20,6\% do total de 92 localidades -, sendo, há muitas décadas, considerada uma região em crise, especialmente devido à ausência de dinamismo econômico. Estima-se que o seu Produto Interno Bruto (PIB) esteja em situação de estagnação desde o início dos anos 1980 (RIBEIRO; RODRIGUES; CORREA, 2008), ao lado da queda dos indicadores de desenvolvimento humano, marcada pelo aumento do desemprego, queda da renda e aumento da informalidade, que se refletem, portanto, na crescente desigualdade e indigência (URANI et al., 2006).

Trata-se, portanto, de um estudo de caráter exploratório (KETELE; ROEGIERS, 1993), metodologicamente ancorado na análise de conteúdo (BARDIN, 2004), em particular de documentos legislativos - planos propriamente ditos e suas leis de criação - (RODRIGUES, 2011), que objetiva contribuir para as reformulações e adequações que o novo PNE (BRASIL, 2014) implica para a reformulação dos planos locais existentes, assim como para aqueles em vias de elaboração. Deriva de pesquisa de maior amplitude, também de natureza qualitativa e de caráter teórico-empírico, que, além das vinculações com outros instrumentos de gestão, objetivou examinar os processos de discussão, elaboração, aprovação, implantação, acompanhamento e avaliação desses mesmos planos ${ }^{1}$.

Além da presente introdução, o estudo encontra-se estruturado por meio de outras seis seções. Principia informando sobre a disseminação dos PMEs no estado do Rio de Janeiro, pós-aprovação do PNE 2001-2010, para, na sequência, proceder à análise da previsão da vinculação desses PMEs em relação ao PEE, ao Plano de Desenvolvimento da Educação (PDE), ao Projeto Político Pedagógico (PPP) e, ainda, às Leis do Orçamento (LOs), de modo a culminar, na última seção, na formulação das conclusões finais do estudo.

1- Este estudo se configura em um dos subprodutos do projeto de pesquisa denominado "Os Planos Municipais de Educação (BRASIL) e as Cartas Educativas Municipais (Portugal): perspectiva comparada entre as regiões/áreas metropolitanas do Rio de Janeiro e do Porto" (cf. SOUZA; CASTRO, 2011).

\section{Disseminação dos PMEs no estado do Rio de Janeiro}

0 estado do Rio de Janeiro veio a ter o seu PEE aprovado somente no nono ano de vigência do PNE 2001-2010 - Lei no 5.597, de 18 de dezembro de 2009 (RIO DE JANEIRO, 2009a; 2009b) -, ou seja, às vésperas do término deste plano nacional, cuja elaboração teve início no ano de 2002, por época da constituição, pela Secretaria de Estado de Educação (SEEDUC), da comissão inicialmente responsável por sua elaboração (VALLE; MENEZES; VASCONCELOS, 2010).

Todavia, em 2008, em que pese o fato de o estado ainda não possuir o PEE, curiosamente a Assembleia Legislativa do Estado do Rio de Janeiro (Alerj), por meio de sua Comissão de Educação, buscou conduzir os municípios fluminenses à elaboração dos seus PMEs. Para tanto, promulgou a Lei $\mathrm{n}^{\circ} 5.332$, de 24 de novembro de 2008, prevendo a suspensão de transferências de receitas próprias do estado, "respeitando os limites constitucionais legais” (RIO DE JANEIRO, 2008a, art. 1º), para localidades que até 2010 não tivessem elaborado o seu respectivo plano, com aprovação pela Câmara Municipal.

De acordo com Valle, Menezes e Vasconcelos (2010), conforme informações encaminhadas pelas Secretarias Municipais de Educação (SMEs) à Comissão de Educação da ALERJ, já no início de 2009, apenas 30\% (28) dos 92 municípios do estado, possuíam PME sob a forma de Lei Municipal. A justificativa dos demais se referia, especialmente, à espera pelo PEE, apesar de essas instâncias terem autonomia para o planejamento de suas próprias políticas educacionais. De acordo com Vasconcelos, Peixoto e Vidal (2012), cujo levantamento tomou por base informações da Comissão de Educação da Alerj, em 2011 este quadro havia evoluído para não

2- Agradecemos às importantes contribuições da colega Professora Doutora Maria Celi Chaves Vasconcelos - Universidade do Estado do Rio de Janeiro (UERJ) / Universidade Católica de Petrópolis (UCP) - para a constituição desta seção do estudo. 
mais do que 52\% (48) das localidades fluminenses com PME aprovado por lei, nestes termos, correspondendo a 23 PMEs a menos do total declarado para a Pesquisa de Informações Básicas Municipais (Munic), realizada pelo Instituto Brasileiro de Geografia e Estatística (IBGE), relativa ao ano de 2011 (BRASIL, 2012), pelos municípios fluminense, também em 2011.

Contudo, em dezembro de 2012, após amplo e exaustivo levantamento documental - pautado em pesquisa via internet, telefone e in loco, junto ao setor de arquivo relativo à Comissão de Educação da Alerj -, os autores do presente texto lograram localizar, única e exclusivamente, 33 PMEs e suas respectivas leis, correlatos a 36\% dos 92 municípios do estado, neste caso, 38 planos a menos do total de 71 que fora indicado para a Munic/IBGE (cf. BRASIL, 2012) e quinze a menos do total de planos cujas leis constavam indicadas nos registros da ALERJ (cf. VASCONCELOS; PEIXOTO; VIDAL, 2012).

Daquele universo de 33 PMEs localizados por estes autores, verificou-se que somente dez pertenciam a municípios da RM do estado, expressão de 53\% do total de dezenove localidades que a compõem, conforme consta do Quadro 1.

Quadro 1 - Enquadramento legal dos PMEs da RM do Rio de Janeiro identificados

\begin{tabular}{|c|c|c|c|}
\hline Município & Lei $n^{0}$ & $\begin{array}{c}\text { Data da } \\
\text { aprovação }\end{array}$ & Vigência \\
\hline Itaboraí (2008a; 2008b) & 2.077 & $28 / 11 / 2008$ & $2008-2017^{\star *}$ \\
\hline Japeri (2008a; 2008b) & 2.281 & 19/12/2008 & $2008-2017^{\star \star}$ \\
\hline Maricá (2008) & 1.155 & $10 / 04 / 2008$ & $2008-2018^{*}$ \\
\hline Nilópolis (2001a; 2001b) & 5.982 & $13 / 12 / 2001$ & $2002-2011^{*}$ \\
\hline Niterói (2010; 2008) & 2.610 & $31 / 10 / 2008$ & $2008-2017^{\star \star}$ \\
\hline Queimados (2009a; 2009b) & 972 & 24/12/2009 & 2009-2019* \\
\hline Rio de Janeiro (2008b; 2008c) & 4.866 & 02/07/2008 & $2008-2017^{\star \star}$ \\
\hline São Gonçalo (2006a; 2006b; 2006c) & 56 & 01/08/2006 & $2006-2015^{\star \star}$ \\
\hline Seropédica $(2011 ;$ 2012) & 426 & 02/01/2012 & $2012-2022^{*}$ \\
\hline Tanguá (2009a; 2009b) & 717 & $24 / 11 / 2009$ & $2009-2018^{\star \star}$ \\
\hline \multicolumn{4}{|c|}{$\begin{array}{l}\text { Fonte: Dados da pesquisa } \\
\text { * Período de vigência está explicitado no documento do PME ou na lei } \\
\text { correspondente. } \\
\text { ** Período de vigência não consta explicitado no PME, tampouco na lei } \\
\text { correspondente, tendo sido deduzido a partir da sua data de aprovação, } \\
\text { tendo por base a lógica adotada no PNE 2001-2010. Vale notar que não há } \\
\text { um critério padronizado no que tange à duração nos planos investigados, } \\
\text { pois alguns extrapolam o período decenal. }\end{array}$} \\
\hline
\end{tabular}

Se apenas dez (53\%) dos dezenove municípios que integram a RM do estado do Rio de Janeiro possuem PMEs (isto até dezembro de 2012), também é possível afirmar, com base nos dados do Quadro 1, que o movimento para a elaboração de seus respectivos planos não ocorreu de forma imediata à aprovação do PNE 2001-2010. Afinal, desses dez planos, somente Nilópolis elaborou e aprovou o seu em 2001, ou seja, no mesmo ano em que aquele plano nacional veio a ser regulamentado por lei. Com exceção de Nilópolis, os demais municípios aprovaram seus respectivos planos a partir do $6^{\circ}$ ano de vigência do PNE em questão: São Gonçalo, em 2006; Itaboraí , Japeri, Maricá, Niterói e Rio de Janeiro, em 2008; Queimados e Tanguá, em 2009 e Seropédica, quando a validade do PNE já expirara, em 2012. Vale observar que a maioria não explicita o período de vigência do plano, sendo o mesmo deduzido a partir da data da sua aprovação.

Do ponto de vista das vinculações desses planos com outros instrumentos de gestão local da educação, cabe inicialmente observar que, por meio do seu exame preliminar, constataram-se referências ao PEE, ao PDE, ao PPP e às LOs - Plano Plurianual (PPA), Lei de Diretrizes Orçamentárias (LDO) e Lei Orçamentária Anual (LOA) -, a seguir indicadas, além de considerações sobre o Plano de Cargos e Salários (PCS) e Plano de Carreira (PC) que, por limitações editoriais do presente artigo, não puderam aqui ser enfocadas.

\section{Vinculações com o Plano Estadual de Educação (PEE)}

No âmbito da Lei de Diretrizes e Bases da Educação Nacional (LDBEN) $n^{\circ}$ 9.394, de 20 de dezembro de 1996 (BRASIL, 1996, art. 10, III), verifica-se a determinação de que as políticas e planos estaduais, além de consoantes ao PNE, devem visar não apenas à integração e coordenação de suas ações, mas também às relativas ao âmbito municipal. Embora não aponte obrigatoriedade de os municípios elaborarem os seus PMEs, a reciprocidade 
está posta nos termos de que os municípios também devem organizar os seus sistemas de ensino de forma integrada às políticas e planos educacionais da União e dos estados (BRASIL, 1996, art. 11, inciso I). Tal responsabilização estadual se fará notar também no PNE 20012010, ao lado da consideração de que os PEEs devem fornecer elementos que subsidiem, de modo integrado e articulado, a elaboração de PMEs (BRASIL, 2001, Capítulo VI).

Para Monlevade (2002, p. 58), os PEEs desempenham função estratégica para a efetiva implantação do PNE, na medida em que suas metas somente poderão ser atingidas se “os Planos Estaduais as compatibilizarem pela média de seus Municípios" - motivo pelo qual o envolvimento dessas localidades na elaboração do PEE é de suma importância -, ou então cada município se responsabiliza "por alcançar ou ultrapassar as metas nacionais" (MONLEVADE, 2002, p. 58). De um modo ou de outro, é por meio do PME que a localidade poderá diagnosticar a sua realidade educacional e, em consequência, prever ações planejadas e sistemáticas que visem ao atendimento das demandas identificadas, consoantemente ao PNE e ao PEE.

No entanto, ao que tudo indica, poucos são os PMEs em tela que estabelecem alguma referência ao PEE do Rio de Janeiro, não ultrapassando metade do seu total, e os que assim procedem ou apenas reiteram o compromisso formal de elaborar suas políticas públicas em sintonia tanto com este plano quanto propriamente com o PNE, isto em observância à Constituição Federal (CF) de 1988, como no caso dos municípios de Maricá e o de Seropédica, ou indicam que não puderam considerá-lo pelo fato de até então o estado do Rio de Janeiro não ter aprovado o seu plano (ocorrido, conforme anteriormente destacado, em 2009), situação declarada pelos PMEs de Itaboraí, Queimados e Nilópolis. Mesmo assim, Itaboraí e Queimados esforçam-se em considerar a tese guia que serviu à elaboração deste estado, apresentada na Conferência Estadual de Educação Básica do Rio de Janeiro, realizada em dezembro de
2007, o primeiro a tentar estabelecer coesão dos eixos relacionados ao ensino médio, educação a distância e à formação e valorização dos profissionais da educação a este documento, em especial no que remete à sua oferta pelo estado, enquanto que o segundo apenas declara que o PME foi elaborado em consonância com o documento preliminar em questão. Já Nilópolis, ao tentar minimizar os efeitos decorrentes da ausência do PEE, indica entendimento equivocado a respeito da função desse plano para o PME, na medida em que afirma que, pelo fato deste último ter se pautado no PNE, "não haverá por certo significativas necessidades de correções" (NILÓPOLIS, 2001a, p. 33).

Finalmente, cabe destacar que os demais PMEs em análise - a saber, Japeri, Niterói, Rio de Janeiro, São Gonçalo e Tanguá - não estabelecem explícita ou implicitamente qualquer vinculação com o PEE, sequer mencionando-o no corpo do texto do plano ou da lei que os regulamentam.

\section{Vinculações com o Plano de Desenvolvimento da Educação (PDE)}

O PDE veio a ser lançado, em 2007, pelo governo federal, tratando-se de um plano elaborado pelo Ministério da Educação (MEC), de caráter executivo, apresentado como capaz de identificar e solucionar problemas que afetam a educação no país, sobretudo a educação básica, visando à sua qualidade, em todos os níveis/ etapas e modalidades de ensino, no prazo de quinze anos (BRASIL, 2007). Dentre o conjunto de ações previstas para a consecução do PDE, que inicialmente contou com cerca de 27 programas/diretrizes para, logo em seguida, por sedimentação proporcionada pelo próprio MEC, vir a compreender mais de cinquenta, o governo federal elaborou dois planos imbricados: de um lado, o Plano de Metas Compromisso Todos pela Educação e, de outro, o Plano de Ações Articuladas (PAR), consubstanciados no Decreto $\mathrm{n}^{\circ}$ 6.094, de 24 de abril de 2007 (BRASIL, 2007). 
Nas palavras de Saviani (2007, p. 1.233), o PDE "aparece como um grande guarda-chuva que abriga praticamente todos os programas em desenvolvimento pelo MEC", exprimindo um conjunto de medidas que não se estruturam em torno do binômio objetivos-ações (OLIVEIRA, 2007), tampouco expondo relações, quer entre si, quer em termos do ordenamento jurídico que regula a educação no país, apontando, apenas, múltiplas ações (CURY, 2007), o que dificulta a sua consideração como plano de educação propriamente dito.

Embora o PDE não tenha estabelecido relações com o PNE 2001-2010 (uma das suas maiores fragilidades), o governo federal o considera como expressão da superação de certas limitações deste plano decenal, primordialmente em termos da lacuna deixada em torno da melhoria da qualidade da educação no país, em que pese reconhecer que o PNE exponha um "bom diagnóstico dos problemas educacionais” (BRASIL, 2007, p. 10).

Entretanto, é importante considerar que o PDE veio a ser promovido em meio à vigência do PNE 2001-2010, o que o fez, de certo modo, vir a se sobrepor a este último, tornando-o, arbitrariamente, secundário (SOUSA, 2009). Assim, um dos problemas relativos à implementação do PNE 2001-2010, identificados no balanço realizado pelo Conselho Nacional de Educação (CNE) sobre algumas das suas avaliações institucionais, refere-se, justamente, à "Articulação tardia do PDE e do PAR com os princípios e metas do PNE” (BRASIL, 2009, p. 6), em que pese reconhecer que "[...] muitas metas foram alcançadas (totalmente ou parcialmente), especialmente as relativas à melhoria da qualidade do ensino" (BRASIL, 2009, p. 7).

Reproduzindo a desarticulação anteriormente mencionada, constatou-se que, do conjunto dos dez PMEs sob análise, apenas dois sinalizam alguma vinculação com o PDE, notadamente quando, de forma pontual, destacam o eixo relativo ao financiamento do plano. 0 PME de Itaboraí (2008b, p. 115) menciona o PDE na seção relativa ao diagnóstico do financiamento, associando o padrão de qualidade desejado para a sua rede municipal de ensino à "fixação de um plano com metas", coerentemente ao previsto pelo PDE, afirmando a importância da realização de diagnósticos e da definição de estratégias e custos que garantam aquele padrão. Já o PME de Niterói (2010, p. 19) estabelece vinculações com o PDE no momento em que prevê a assinatura do seu termo de adesão, com vistas à promoção da "sustentabilidade das ações firmadas".

No que tange aos outros oito PMEs, cabe preliminarmente enfatizar que apenas Nilópolis e São Gonçalo não teriam como prever vinculações dos seus respectivos planos com o PDE, uma vez que vieram a ser aprovados em data anterior a do seu lançamento pelo governo federal, respectivamente em 2001 e 2006, enquanto que os demais planos - Japeri, Maricá, Queimados, Rio de Janeiro, Seropédica e Tanguá -, embora posteriormente aprovados (veja-se Quadro 1), sequer chegaram a mencioná-lo.

\section{Vinculações com o Projeto Político Pedagógico (PPP)}

No bojo das reformas educacionais suscitadas pela LDBEN $n^{\circ}$ 9.394/1996, о PPP veio a despontar como uma das possibilidades de consolidação da gestão democrática da educação quer ao nível dos sistemas de ensino, quer, especialmente, no âmbito das unidades escolares, de grande importância, portanto, para o processo de autonomização pedagógica dessas instituições, assim como, em termos sociopolíticos, em relação à comunidade local. De modo subjacente, o PPP pode ser tomado como uma das expressões das políticas de descentralização que, após a CF/1988, passou a influenciar a gestão da educação pública no país, embora, na prática, tenham convergido para um perfil de maior concentração de poder conjugado à mera transferência institucional de competências e responsabilidades.

Na Lei no 9.394/1996, a importância de a instituição escolar defınir seus próprios objetivos 
e estratégias pedagógicas de modo coeso às especificidades da sua ambiência interna $e$ externa é indicada por meio de referências ao que denomina ora por "proposta pedagógica", ora por "projeto pedagógico", mantendo, ao longo do texto legal, esta dualidade de nomenclaturas. Determina, com sito, que os estabelecimentos de ensino devem "elaborar e executar sua proposta pedagógica” (BRASIL, 1996, art. 12, I), também devendo "informar pais e responsáveis sobre [...] a sua execução" (BRASIL, 1996, art. 12, VII) ${ }^{3}$, destacando, ainda, que caberá aos docentes "participar da elaboração da proposta pedagógica do estabelecimento de ensino" (BRASIL, 1996, art. 13, I). Já em outro momento, estabelece que as normas referentes à implantação da gestão democrática devam ser definidas pelos sistemas de ensino tanto de modo coeso às sua particularidades, quanto em observância à "participação dos profissionais da educação na elaboração do projeto pedagógico da escola" (BRASIL, 1996, art. 14, I), cabendo à comunidade local participar "em conselhos escolares ou equivalentes” (BRASIL, 1996, art. 14, II). Esses dois princípios irão se consubstanciar em um dos objetivos centrais do PNE 2001-2010, quando inicialmente destaca que a "democratização da gestão do ensino público, nos estabelecimentos oficiais” (BRASIL, 2001), deverá observar os processos participativos dos profissionais da educação e da comunidade, e, mais adiante, configura o PPP "como a própria expressão da organização educativa da unidade escolar" (BRASIL, 2001) articulada ao surgimento dos Conselhos Escolares.

A importância atribuída ao PPP nesses marcos legais decorre do fato de que este componente da gestão escolar potencialmente se configura como eixo norteador das práticas intraescolares, trazendo consigo sentidos e proposições políticas coletivas construídas com base na participação de diversos atores sociais

3- Inciso alterado pela Lei no 12.013, de 06 de agosto de 2009 (BRASIL, 2009), quando destaca que os estabelecimentos de ensino deverão "informar pai e mãe, conviventes ou não com seus filhos, e, se for o caso, os responsáveis legais [...] sobre a execução da proposta pedagógica da escola". (direção, professores, alunos, pais/responsáveis e, de um modo mais amplo, comunidade escolar). Faculta, portanto, o "engajamento coletivo para integrar ações dispersas” (VEIGA, 2003, p. 275), criando "sinergias no sentido de buscar soluções alternativas para diferentes momentos do trabalho pedagógico-administrativo" (VEIGA, 2003, p. 275), entre outras propriedades.

Do ponto de vista do conjunto dos PMEs sob análise, cabe inicialmente destacar que todos esses dez planos realizam alguma referência ao PPP, embora apenas quatro forneçam elementos que permitam postular a existência de previsões de vinculações entre as decisões indicadas. Assim, Itaboraí, Rio de Janeiro, São Gonçalo e Tanguá estatuem vinculações de modo relativamente sistemático e, em certa medida, regular entre o conjunto de decisões concernentes aos eixos enfocados, sendo o plano do Rio de Janeiro aquele que mais referências faz ao PPP. Observa-se, portanto, que o PPP é contemplado nos objetivos e metas relativos às etapas e modalidades de educação de que tratam - dependendo do plano, no âmbito da educação infantil, ensino fundamental, educação de jovens e adultos, educação especial, educação a distância e educação profissional -, assim como em outros eixos temáticos que os compõem - formação dos profissionais de educação (Tanguá) e tecnologias de informação e comunicação (Itaboraí) -, inclusive no caso de temas de maior especificidade - meio ambiente (São Gonçalo, Tanguá), educação, sexualidade e gênero (Tanguá).

Entretanto, o PPP parece assumir relevo nesses quatro planos a partir de preocupações tipicamente curriculares e não político-administrativas ou sociopolíticas, sendo raras as referências à sua contribuição para a autonomização das unidades escolares, ou mesmo para a gestão democrática da educação local nos termos de vir a sinalizar o valor dos processos participativos na sua elaboração, também com vistas à sua legitimação social.

Sobre a autonomia da unidade escolar, São Gonçalo (2006c, p. 5) indica como meta do 
eixo ensino fundamental que $100 \%$ das suas escolas a conquistem em termos do projeto pedagógico e dos "recursos financeiros públicos municipais, suficientes para a manutenção do cotidiano escolar", enquanto que o Rio de Janeiro (2008c, p. 41) entende o exercício da autonomia escolar como pressupondo medidas fundamentais, entre outras, concernentes à "elaboração do projeto político próprio, de acordo com as características regionais e locais, com a participação da comunidade escolar", ressaltando a importância da:

[..] participação dos membros dos diferentes Conselhos Escolares [por exemplo, Escola-Comunidade e Grêmio Estudantil], como forma de enfatizar a ação democrática garantida pela representatividade" (RIO DE JANEIRO, 2008c, p. 37).

Já no caso da gestão democrática da educação, nos termos do exercício da participação sociopolítica da comunidade na construção do PPP, Tanguá (2009a, p. 120) a vê como "um importante passo para construir movimentos instituintes de relações verdadeiramente democráticas" nas suas escolas, não havendo maiores referências nos demais planos a respeito desta dimensão.

Nos demais PMEs, as previsões de sua vinculação ao PPP se mostram meramente formais ou se caracterizam parciais. No primeiro caso, os planos de Maricá, Seropédica e Queimados citam ligeiramente o PPP, os dois primeiros, apenas no momento em que apresentam os macro-objetivos do plano, destacando sua importância para a democratização, de um modo amplo, da educação e, de forma particular, da escola, enquanto que no terceiro plano o PPP é unicamente mencionado na transcrição de um texto relativo a uma palestra proferida na abertura da Conferência Municipal de Educação de Queimados, realizada em setembro de 2009. Assim, em nenhuma outra seção desses planos se verifica a formulação de objetivos e metas que implícita ou explicitamente assegure a efe- tivação do PPP, ou mesmo a sua consideração para a garantia da realização de algumas dessas decisões, o que descaracteriza, portanto, a existência de quaisquer vinculações, de fato, relacionadas ao PME. Outro conjunto de PMEs se caracteriza por designar vinculações parciais ao PPP, pois enfoca apenas as etapas da educação básica, não o relacionando a outros objetivos e metas do plano. Assim, Nilópolis vincula ao PPP algumas das decisões relativas à educação infantil e ao ensino fundamental, enquanto que Niterói e Japeri, em exclusivo, ao ensino fundamental, todos, caracteristicamente, com preocupações curriculares, recomendando a observação de referenciais, diretrizes e parâmetros curriculares de âmbito nacional, também advertindo acerca da importância de considerar neste processo temáticas transversais adequadas à realidade das unidades escolares.

\section{Vinculações com as Leis do Orçamento (LOs)}

Inicialmente, é importante salientar que todos os planos ora pesquisados foram aprovados após a edição da Lei Complementar $\mathrm{n}^{\circ} 101$, de 4 de maio de 2000 (BRASIL, 2000), conhecida como Lei de Responsabilidade Fiscal (LRF), que fixou normas para o campo de finanças públicas que implicassem responsabilidade na gestão fiscal, estabelecendo com isso um código de conduta com vistas ao equilíbrio das contas públicas, entre receitas e despesas. Embora haja distintas visões em torno dos efeitos da LRF, para Aguiar (2002), esta lei foi benéfica, pois implicou uma nova maneira de governar, requerendo não só uma racionalidade nos gastos públicos, como também tirou “da ficção os planos plurianuais para torná-los instrumentos de planejamento para o longo prazo, a serem realmente seguidos" (AGUIAR, 2002, p. 41). Considerando as exigências postas pela LRF e as responsabilidades imputadas aos municípios pela legislação atinente à área da educação, um PME não poderia (e não pode) 
perder de vista as devidas articulações com outros instrumentos de gestão municipal, em especial na área de finanças, para que o mesmo tenha maiores chances de ser efetivado.

Nessa área, os instrumentos de gestão municipal citados nos planos analisados foram o PPA, a LDO e a LOA, os quais consistem em planejamentos orçamentários previstos no art. 165, da CF/1988 (BRASIL, 1988). Segundo Torres (2013, p. 172), especialista da área do direito financeiro e tributário, esses três planejamentos "se integram harmoniosamente, devendo a lei orçamentária anual respeitar as diretrizes orçamentárias, consonando ambas com o orçamento plurianual”. Assim, o PPA não é somente um instrumento de planejamento previsto constitucionalmente, mas ganha relevância ao elencar as diretrizes que devem ser respeitadas tanto na LDO quanto na LOA. Trata, portanto, de uma questão fulcral quando se aborda planejamento: disponibilidade fınanceira para a organização de um orçamento, sobretudo com a aprovação da LRF.

Além disso, como o próprio nome sugere, o PPA não se restringe a um ano, já que esse plano fornece as bases orçamentárias para o cumprimento de ações e programas de média duração. 0 PPA possui vigência de quatro anos e deve ser elaborado e aprovado no primeiro ano de um governo. Ou seja, seu prazo de validade se inicia no segundo ano do mandato do gestor que o elaborou e expira ao final do primeiro ano do governo seguinte. Ao ultrapassar o mandato do representante do poder executivo, o PPA tem o intuito de dar continuidade às ações iniciadas, sendo, portanto, uma ferramenta de planejamento essencial que deve:

[...] discriminar os programas e as ações que o governo pretende implementar, [...] as metas físicas por tipo de programa e ação, além das despesas de caráter continuado, a fim de condicionar a programação orçamentária anual ao planejamento de médio prazo. (ROCHA; MONLEVADE; AGUIAR, 2006, p. 92).
Dos sete municípios que mencionaram o PPA, cinco o apontaram em seus respectivos planos no eixo financiamento (Japeri, Nilópolis, Niterói, Queimados e São Gonçalo) e um no bojo da própria lei (Rio de Janeiro). Tais municípios explicitaram que os PPAs vigentes para os próximos dez anos deveriam dar suporte financeiro para a concretização das metas constantes no PME. Itaboraí também incluiu o PPA, porém com uma perspectiva distinta dos demais municípios. Em seu PME, um dos objetivos previa:

[...] fornecer uniforme completo (de verão e inverno), calçados, mochila e kit escolar para todos os alunos da Educação Infantil da rede pública. (ITABORAÍ, 2008b, p. 23).

Tal fornecimento, entretanto, somente seria efetivado se estivesse contemplado no PPA. Há, portanto, um olhar oposto se comparado aos demais municípios. A maioria citou que os PPAs deveriam acolher as metas do PME, não cabendo, portanto, uma subalternização do PME em relação ao PPA, até porque a vigência deste é inferior (quadrienal) ao do PME, que é decenal.

Dois municípios deram um maior destaque a esses instrumentos de gestão financeira. Japeri, além de ter citado a LOA e PPA no eixo do financiamento, apontou, igualmente, que se deveriam garantir no PPA e na LDO recursos para a contratação de profissionais e oferta de programas voltados à educação especial, como também destacou a necessidade de se acompanhar a LDO para a aplicação do percentual destinado à educação, ao propor programas atinentes à educação de jovens e adultos. Queimados apontou as mudanças advindas na organização orçamentária a partir da Constituição Federal/88, destacando o papel do PPA, LDO e LOA no planejamento do executivo.

\section{Considerações finais}

Segundo Maricato (2011), há uma precariedade em torno do quadro legal de RMs 
no Brasil, caracterizada por diferenciações demográficas, econômicas, sociais e políticas, decorrente da pluralidade de critérios adotados para a sua criação entre os estados da federação, que se agrava, de um lado, pela prevalência de programas de investimentos esporádicos e de natureza setorial nessas regiões, e, de outro, conforme ressaltado por Souza (2003), pela incipiente cooperação intermunicipal.

Entre outros aspectos, a análise dos dez PMEs da RM do Rio de Janeiro até aqui levada a efeito revela, justamente, uma nítida tendência à baixa cooperação intermunicipal. Em nenhum momento do processo de análise, observou-se qualquer referência a determinados desafios educacionais que viessem a implicar definição de ações de gestão conjunta dessas cidades ditas intermunicipais - que, de certo, a par das suas especificidades, enfrentam problemas urbanos complexos e similares -, ou mesmo o registro do reconhecimento de que a cooperação com outras localidades metropolitanas poderia ou deveria vir a ser observada nas políticas locais que dessem corpo às decisões do plano.

Se a ausência de um enfoque regionalmetropolitano nesses PMEs caracteriza certo isolamento entre os planejamentos locais da educação, e entre esses e um possível planejamento integrado para a área, coordenado pelo estado, a desvinculação observada em relação a outros instrumentos de gestão municipal da educação acaba por deslocálos para uma espécie de exílio, colocando em dúvida a exequibilidade desses planos.

Conforme constatado, essa desvinculação se sobressai em relação ao conjunto de instrumentos de gestão considerados nas análises, sendo registrada na quase totalidade dos PMEs enfocados. Começa a se manifestar na ausência de previsões quanto à articulação com o PEE, e também, possivelmente, em função dos efeitos causados pela inexistência desse plano no estado do Rio de Janeiro - que somente veio a ser aprovado às vésperas do término do PNE 2001-2010 -, o que debilita a tradução local desse plano nacional. A desvinculação em questão se torna evidente em face da desconsideração do PDE e dos planos que lhe dão sustentação - Plano de Metas Compromisso Todos pela Educação e o PAR -, dissociação que originalmente se encontra posta na relação do próprio PDE para com o PNE, mas que não necessariamente teria que se reproduzir em âmbito municipal, já que é nesse território que o PDE, de fato, se consubstancia, em especial por meio dos diagnósticos e ações do PAR, tendo à frente o protagonismo local.

Todavia, o exame desses dez PMEs aponta maior adensamento relativo de vinculações quando se trata das LOs e especialmente dos PPPs, em que pese o fato de ainda continuarem circunscritas a poucos planos. No caso das LOs, os planos que no mínimo mencionaram o PPA sugerem reconhecer que o PME, por si só, não oferece garantias para a sua implantação, pois concretamente depende de relações e determinações legais que extrapolam sua área estrita, a começar pela das finanças. Ainda assim, apenas dois planos chegaram a mencionar, além do PPA, a LDO e a LOA, significando que suas metas e objetivos tendem a estar calçados em previsões financeiras que viabilizem jurídica e tecnicamente a efetivação do plano. Já no que remete ao PPP, pouquíssimos são os planos que, de fato, estabelecem previsões de vinculações consistentes e sistemáticas e, sobretudo, que considerem o seu papel na construção da autonomia das unidades escolares e da gestão democrática da educação local, em que pese o fato de todos esses documentos o mencionarem. Conforme visto, na maior parcela dos PMEs analisados, as previsões de sua vinculação ao PPP oscilam entre citações tipicamente formais, expressão da retórica pedagógica que em larga medida modula a construção desses planos, e ocorrências assistemáticas e pontuais, reflexo da fragmentação que internamente os marca.

Por fim, é possível afırmar que a reformulação desses PMEs com vistas à sua adequação às vinte decisões do PNE 2014-2020 esbarra no desafio, entre outros, de superação das desvinculações observadas, na perspectiva 
de prevê-las ao nível regional e local. Tais enlaces são passíveis de predição a partir da compreensão de que um plano de educação não possui um fim em si mesmo, não se constituindo, portanto, como um instrumento independente e suficiente de gestão. Embora se afigure num registro de coordenação e sistematização das decisões previstas para a condução das políticas educacionais no município, vale frisar que o PME é parte integrante dessas mesmas políticas e não estranho a elas. Em consequência, deve ser concebido como dispositivo técnico e político de planejamento local da educação, nos termos de não apenas se portar processualmente como sua expressão, mas, a um só tempo, como forma privilegiada de intervenção nas múltiplas realidades regionais e locais.

\section{Referências}

AGUIAR, Ubiratan. Lei de Responsabilidade Fiscal - LRF, financiamento da educação básica e Plano Municipal de Educação - PME. Revista Educação Municipal, Brasília, DF, n. 5, p. 35-43, 2002.

ASSUMPÇÃO, Eracilda de. Plano Municipal de Educação: dá intenção à ação. In: WERLE, Flávia Obino Correa (Org.). Sistema municipal de ensino e regime de colaboração. ljuí: Unijuí, 2006. p. 137-154.

BARBOZA, Edir Neves. A constituinte em Dourados (2000-2004): um movimento em busca da democratização da escola pública. Dourados, 2008. 208 f. Dissertação (Mestrado em Educação) -Fundação Universidade Federal do Mato Grosso do Sul, 2008.

BARDIN, Laurence. Análise de conteúdo. 3. ed. Lisboa: Edições 70, 2004.

BRASIL. Constituição [de 1988] da República Federativa do Brasil. Diário Oficial da União, Brasília, DF, 5 out. 1988.

BRASIL. Decreto n 6.094, de 24 de abril de 2007. Dispõe sobre a implementação do Plano de Metas Compromisso Todos pela Educação, pela União Federal, em regime de colaboração com municípios, Distrito Federal e Estados, e a participação das famílias e da comunidade, mediante programas e ações de assistência técnica e financeira, visando a mobilização social pela melhoria da qualidade da educação básica. Diário Oficial da União, Brasília, DF, 25 abr. 2007.

BRASIL. Lei nº 9.394, de 20 de dezembro de 1996. Estabelece as Diretrizes e Bases da Educação Nacional. Diário Oficial da União, Brasília, DF, Brasília, DF, 23 dez. 1996.

BRASIL. Lei ñ 10.172, de 09 de janeiro de 2001. Aprova o Plano Nacional de Educação (PNE). Diário Oficial da União [da] República Federativa do Brasil, Brasilia, DF, 10 jan. 2001.

BRASIL. Lei no 12.013, de 06 de agosto de 2009. Altera 0 art. 12 da Lei no 9.394, de 20 de dezembro de 1996, determinando às instituições de ensino obrigatoriedade no envio de informações escolares aos pais, conviventes ou não com seus filhos. Diário Oficial da União, Brasília, DF, 07 ago. 2009.

BRASIL. Lei no 13.005, de 25 de junho de 2014. Aprova o Plano Nacional de Educação - PNE e dá outras providências. Diário Oficial da União, Braślia, DF, 26 jun. 2014.

BRASIL. Lei Complementar n 101, de 4 de maio de 2000. Estabelece normas de finanças públicas voltadas para a responsabilidade na gestão fiscal e dá outras providências. Diário Oficial da União, Brasília, DF, 5 maio 2000.

BRASIL. Conselho Nacional de Educação. Portaria CNE/CP n 10, de 6 de agosto de 2009: indicações para subsidiar a construção do Plano Nacional de Educação 2011-2020. Brasília, DF: CNE/CP, 2009.

BRASIL. Instituto Brasileiro de Geografia e Estatística. Diretoria de Pesquisas. Coordenação de População e Indicadores Sociais. 
PERFIL DOS municípios brasileiros 2011. Rio de Janeiro: IBGE, 2012.

BRASIL. Ministério da Educação. 0 Plano de Desenvolvimento da Rducação: razões, princípios e programas. Brasília, DF: MEC, 2007.

CARVALHO, Inaiá Maria Moreira de; PASTERNAK, Suzana; BOGUS, Lúcia Machado. Transformações metropolitanas: São Paulo e Salvador. Caderno CRH, Salvador, v. 23, n. 59, p. 301-321, 2010.

CURY, Carlos Roberto Jamil. Impacto sobre as dimensões de acesso e qualidade. In: GRACIANO, Mariângela (Org.). 0 Plano de Desenvolvimento da Educação. v. 4. São Paulo: Ação Educativa, 2007. p. 14-15.

DRABACH, Neila Pedrotti; MIRANDA, Natália Pergher. Uma análise sobre a participação na construção do Plano Municipal de Educação de Santa Maria, RS. In: SIMPÓSIO BRASILEIRO DE POLíTICA E ADMINISTRAÇÃO DA EDUCAÇÃO, 22., 2005, Rio de Janeiro. Anais... Rio de Janeiro: ANPAE, 2005.

GHENO, Eliane Terezinha. Políticas educacionais e processo de divulgação: 0 caso do Plano Municipal de Educação de Esteio. 2008. 148 f. Dissertação (Mestrado em Educação) - Centro de Ciências Humanas, Universidade do Vale do Rio dos Sinos (Unisinos), São Leopoldo, 2008.

ITABORÁ́. Lei nº 2.077, de 28 de novembro de 2008. Institui o Plano Municipal de Educação de Itaboraí. Jornal Itaboraí, Itaboraí, n. 138,29 nov. 2008 a.

ITABORAÍ. Plano Municipal de Educação de Itaboraí: anexo da lei nº 2.077, de 28 de novembro de 2008. Itaboraí: Câmara Municipal, 2008b.

JAPERI. Lei ñ 1.155, de 10 de abril de 2008. Aprova o Plano Municipal de educação e dá outras providências. Diário da Câmara dos Deputados, Japeri, 10 abr. 2008a.

JAPERI. Plano Municipal de Educação: município de Japeri. Japeri: Secretaria Municipal de Educação e Cultura: Conselho Municipal de Educação, 2008b.

KETELE, Jean-Marie de; ROEGIERS; Xavier. Metodologia da recolha de dados: fundamentos dos métodos de observações, de questionários, de entrevistas e de estudo de documentos. Lisboa: Instituto Piaget, 1993. (Coleção epistemologia e sociedade).

LACERDA, Alan Daniel Freire de. Ação coletiva e cooperação intermunicipal em duas metrópoles. Caderno CRH, Salvador, v. 24, n. 61, p. 153-166. 2011.

MARICÁ. Lei n 2.281, de 19 de dezembro de 2008. Aprova o Plano Municipal de Educação. Jornal Oficial de Maricá, Maricá, v. 2, n. 129, 29 dez. 2008.

MARICATO, Erminia. Metrópoles desgovernadas. Estudos Avançados, São Paulo, v. 25, n. 71, p. 7-22, 2011.

MARICATO, Erminia. Urbanismo na periferia do mundo globalizado: metrópoles brasileiras. São Paulo em Perspectiva, São Paulo, v. 14, n. 4, p. 21-33, 2000.

MARTINS, Angela Maria; PIMENTA, Cláudia Oliveira; NOVAES, Gláucia Torres Franco. Planos municipais de educação: potencialidades e limites de municípios na elaboração de instrumentos de planejamento. In: SOUZA, Donaldo Bello de; MARTINS, Ângela Maria (Org.). Planos de educação no Brasil: planejamentos, políticas, práticas. São Paulo: Loyola, 2014. p. 277-302.

MONLEVADE, João Antônio Cabral de. Como elaborar o Plano Municipal de Educação. Revista Educação Municipal, Brasília, DF, n. 5, p. 55-69, 2002.

NILÓPOLIS. Anexo a Lei n 5.982, de 29 de novembro de 2001: Plano Municipal de Educação. Nilópolis: Secretaria Municipal de Educação, 2001a.

NILÓPOLIS. Lei n 5.982, de 13 de dezembro de 2001. Aprova o Plano Municipal de Educação com previsão de vigência de 2002 a 2011, e dá outras providências. Jornal A Voz dos Municípios Fluminenses, Nilópolis, 28 dez. 2001b.

NITERÓl. Lei nº 2.610, de 31 de outubro de 2008. Aprova o Plano Municipal de Educação de Niterói e dá outras providências. A 
Tribuna, Niterói, 01 nov. 2008.

NITERÓl. Lei nº 2.707, de 25 de março de 2010. Aprova a Complementação do Plano Municipal de Educação de Niterói e dá outras providências. Jornal 0 Fluminense, Niterói, 25 mar. 2010.

OLIVEIRA, Maria José Houly Almeida de; ARAGÃO, Maria Helena de Melo. Plano Municipal de Educação - PME: a experiência do município de Arapiraca. In: COLÓQUIO INTERNACIONAL EDUCAÇÃO E CONTEMPORANEIDADE, 4., 2010, Laranjeiras. Anais... Laranjeiras: UFS.

OLIVEIRA, Romualdo Portela de. Qualidade com garantia de respeito às diversidades e necessidades de aprendizagem. In: GRACIANO, Mariângela (Org.). 0 Plano de Desenvolvimento da Educação. São Paulo: Ação Educativa, 2007. p. 32-34.

QUEIMADOS. Lei n 972, de 24 de dezembro de 2009: Aprova o Plano Municipal de Educação de Queimados e dá outras providências. Queimados: Gabinete do Prefeito, 2009a.

QUEIMADOS. Plano Municipal de Educação: Queimados 2009-2019. Queimados, Secretaria Municipal de Educação, 2009b.

RIBEIRO, Luiz Cesar de Queiroz; RODRIGUES, Juciano Martins; CORREA, Filipe Souza. Território e trabalho: segregação e segmentação urbanas e oportunidades ocupacionais na Região Metropolitana do Rio de Janeiro. In: ENCONTRO NACIONAL DE ESTUDOS POPULACIONAIS, 16., 2008, Caxambu. Anais... Campinas: ABEP, 2008. Disponível em: <http://www.abep. nepo. unicamp. br/encontro2008/docsPDF/ABEP2008_1743.pdf>. Acesso em: 16 nov. 2011.

RI0 DE JANEIRO (Estado). Lei $n^{0} 5.332$, de 24 de novembro de 2008. Dispõe sobre as transferências de receita aos municípios que constituírem o Plano Municipal de Educação. Diário Oficial do Estado, Rio de Janeiro, 25 nov. $2008 \mathrm{.}$.

RIO DE JANEIRO (Estado). Lei no 5.597, de 18 de dezembro de 2009. Institui o Plano Estadual de Educação - PEE-RJ, e dá outras providências. Diário Oficial do Estado, Rio de Janeiro, 19 de dez. 2009a.

RIO DE JANEIRO (Estado). Plano Estadual de Educação do Rio de Janeiro. Rio de Janeiro: Secretaria de Educação, 2009b.

RIO DE JANEIRO (Estado). Fundação Centro Estadual de Estatísticas, Pesquisas e Formação de Servidores Públicos do Rio de Janeiro. Anuário estatístico do Estado do Rio de Janeiro 2010. Rio de Janeiro: CEPERJ, 2010. 1 CD-ROM.

RIO DE JANEIRO (Município). Lei nº 4.866, de 02 de julho de 2008. Aprova o Plano Municipal de Educação e dá outras providências. Diário Oficial do Município do Rio de Janeiro, Rio de Janeiro, 04 jul. 2008b.

RIO DE JANEIRO (Município). Plano Municipal de Educação da cidade do Rio de Janeiro. Rio de Janeiro: Secretaria Municipal de Educação, 2008c.

ROCHA, Denise Cristina Corrêa da; MONLEVADE, João Antonio Cabral de; AGUIAR Rui Rodrigues. Financiamento e gestão orçamentária da educação. In: BRASIL. Ministério da Educação. Secretaria de Educação Básica. Pradime: Programa de Apoio aos Dirigentes Municipais de Educação. Brasília, DF: MEC/SEB, 2006. p. 73-118. (Caderno de textos, 2).

RODRIGUES, Lea Carvalho. Análises de conteúdo e trajetórias institucionais na avaliação de políticas públicas sociais: perspectivas, limites e desafios. CA0S - Revista Eletrônica de Ciências Sociais, João Pessoa, n. 16, p. 55-73, mar. 2011.

SANTOS, Ana Lúcia Ribeiro dos. Plano e gestão da educação municipal: relação entre proposta e efetivação. 2004. 225f. Dissertação (Mestrado em Educação) -Universidade Federal do Paraná. Curitiba, 2004.

SÃO GONÇALO. Lei no 056, de 01 de agosto de 2006. Aprova o Plano Municipal de Educação e dá outras providências. Atos Oficiais, São Gonçalo, 24 ago. 2006a.

SÃo GONÇALO. Parecer CME n⿳000 005, de 21 de outubro de 2004. Delibera sobre o Plano Municipal de Educação de São Gonçalo. Atos Oficiais, São Gonçalo, 24 ago. $2006 \mathrm{~b}$. 
SÃO GONÇALO. Plano Municipal de Educação de São Gonçalo - 2004. Atos Oficiais, São Gonçalo, 24 ago. 2006c.

SAVIANI, Dermeval. 0 Plano de Desenvolvimento da Educação: análise do projeto do MEC. Educação \& Sociedade, Campinas, v. 28, n. 100, p. 1231-1255, out. 2007.

SEROPÉDICA. Lei nº 426, de 02 de janeiro de 2012. Institui o Plano Municipal de Seropédica. Seropédica: Câmara Municipal, 2012.

SEROPÉDICA. PME - Plano Municipal de Seropédica. Seropédica: Prefeitura Municipal; Secretaria Municipal de Educação, 2011. SOUSA, Bartolomeu José Ribeiro de. Os planos e a educação básica no Brasil - 0 PDE em análise. In: SIMPÓSIO BRASILEIRO DE POLÍTICA E ADMINISTRAÇÃO DA EDUCAÇÃO, 24., 2009, Vitória. Anais... Rio de Janeiro: ANPAE, 2009.

SOUZA, Celina. Regiões metropolitanas: condicionantes do regime político. Lua Nova, São Paulo, n. 59, p. 137-158, 2003.

SOUZA, Donaldo Bello de; CASTRO, Dora Fonseca de. Projeto de investigação - 0s Planos Municipais de Educação (Brasil) e as Cartas Educativas Municipais (Portugal): perspectiva comparada entre as Regiões/Áreas Metropolitanas do Rio de Janeiro e do Porto. Rio de Janeiro: Nephem/FE/UERJ; Porto: InEd/Esse/IPPorto, 2012.

SOUZA, Donaldo Bello de; DUARTE, Marisa Ribeiro Teixeira. Planos de educação no Brasil: projeções do sistema nacional de educação e suas variantes subnacionais. In: SOUZA, Donaldo Bello de; MARTINS, Ângela Maria (Org.). Planos de educação no Brasil: planejamentos, políticas, práticas. São Paulo: Loyola, 2014. p. 209-232.

SOUZA, Donaldo Bello de; MENEZES, Janaína Specht da Silva. Estudo crítico-exploratório sobre os Planos Estaduais de Educação (PEEs) no Brasil: contribuições para formulações e reformulações decorrentes do novo Plano Nacional de Educação (PNE) - Relatório de pesquisa. Rio de Janeiro: Nephem/UERJ; Neephi/Unirio, 2014.

SOUZA, Donaldo Bello de; SOUSA, Gustavo José Albino de. Planos nacionais, estaduais e municipais de educação no Brasil: balanço quali-quantitativo sobre a literatura acadêmica (1996-2010). Agenda Social, Campos dos Goytacases, v. 6, p. 50-70, 2012.

SOUZA, Márcio Jocerlan de. Processo de elaboração do plano municipal de educação do Assú/RN e a participação dos professores. 2006. 142 f. Dissertação (Mestrado em Educação) - Universidade Federal do Rio Grande do Norte, Natal, 2006.

TANGUÁ. Lei nº 0717, de 24 de novembro de 2009. Institui o Plano Municipal de Educação. Tanguá: Gabinete do Prefeito, $2009 a$.

TANGUÁ. Plano Municipal de Educação. Tanguá: Prefeitura Municipal: Secretaria de Educação, Esporte e Lazer, 2009b.

TORRES, Ricardo Lobo. Curso de direito financeiro e tributário. 19. ed. Rio de Janeiro: Renovar, 2013.

URANI, André et al. Risco social na Região Metropolitana do Rio de Janeiro: um quadro sobre as condições socioeconômicas das crianças e jovens 1995-2003. Rio de Janeiro: IETS, 2006. Disponível em: <http://www.iets.org.br/biblioteca/Risco_social_ na_RM_do_RJ.pdf>. Acesso em: 16 nov. 2011.

VALLE, Bertha de Borja Reis do; MENEZES, Janaina Specht da Silva; VASCONCELOS, Maria Celi Chaves. Plano Estadual de Educação do Rio de Janeiro: a trajetória de uma legislação. Rio de Janeiro: Quartet: Outras Letras, 2010.

VASCONCELOS, Maria Celi Chaves; PEIXOTO, Leonardo Ferreira; VIDAL, Patrícia Evaristo. Conselhos Municipais de Educação no estado do Rio de Janeiro: uma análise comparativa a partir do Sicme. In: VALLE, Bertha de Borja Reis do; VASCONCELOS, Maria Celi Chaves (Orgs.). Conselhos municipais de educação: organização e atribuições nos sistemas de ensino do Estado do Rio de Janeiro. Rio de Janeiro: Quartet: Faperj, 2012. p. 305-339.

VEIGA, IIma Passos Alencastro. Inovações e projeto político-pedagógico: uma relação regulatória ou emancipatória? Cadernos CEDES, Campinas, v. 23, n. 61, p. 267-281, dez. 2003.

VILLELA, Viviane Merlim Moraes. 0 conceito de cidadania na definição de políticas públicas educacionais: debates e impasses no processo de elaboração do Plano Municipal de Educação de Niterói/RJ. Niterói, 2008. 245 f. Dissertação (Mestrado em Educação) -Universidade Federal Fluminense, Niterói, 2008. 
WERLE, Flávia Obino Corrêa; BARCELLOS, Jorge Alberto Soares. Plano Municipal de Educação e a afirmação de princípios para a educação local. Ensaio, Rio de Janeiro, v. 16, n. 61, p. 515-542, out./dez. 2008.

Donaldo Bello de Souza é professor associado no Departamento de Políticas Públicas, Avaliação e Gestão da Educação (DEPAG) e coordenador do Núcleo de Estudos em Política e História da Educação Municipal (NEPHEM) na Faculdade de Educação da Universidade do Estado do Rio de Janeiro (Uerj). É membro da Comissão Assessora de Especialistas para Avaliação de Políticas Educacionais no Ministério da Educação / Instituto Nacional de Estudos e Pesquisas Educacionais Anísio Teixeira (MEC/Inep).

Alzira Batalha Alcântara é professora da Universidade do Estado do Rio de Janeiro, Departamento de Ciências e Fundamentos da Educação, da Faculdade de Educação da Baixada Fluminense (FEBF/Uerj). Desde 2010, integra 0 corpo docente do curso de pós-graduação lato sensu Organização curricular da educação básica, na FEBF/Uerj. Integra, desde fevereiro 2013, 0 corpo docente do Programa de Pós-Graduação em Educação (PPGE) da Unesa, e ocupa, desde 2014, 0 cargo de coordenadora da linha Políticas, Gestão e Formação de Professores (PFGE). 